Abstract ID: 40

\title{
Aggressive vertebral hemangioma in paediatric spine with cord compression
}

Ed Simor Khan Mor Japar Khan ${ }^{\mathrm{a}} \mid{\text { Dzulkarnain } \text { Amir }^{\mathrm{b}} \mid \text { Manmohan Singh }}^{\mathrm{b}}$ | Goh Jin Hee ${ }^{\mathrm{b}}$ | Nor Azlin Zainal Abidin ${ }^{\mathrm{b}}$ | Fazir Mohamad ${ }^{\mathrm{b}}$

${ }^{a}$ Department of Orthopaedics, Traumatology \& Rehabilitation, Kulliyyah of Medicine, International Islamic University Malaysia

${ }^{b}$ Department of Orthopaedic and Traumatology, Hospital Kuala Lumpur

Vertebral body hemangiomas are benign primary vascular tumours and account for $4 \%$ of all spinal tumours. The majority of patients are asymptomatic. They affect male and female equally. The majority has seen in middle age group. An aggressive vertebral hemangioma presenting with neurological deficits are rare, accounting for less than $1 \%$ in the general population. A 10 year old girl with a two weeks history of unsteady gait, frequent falls and back pain which was preceded by a history of traumatic compression fracture of T10 vertebrae. Examination revealed upper motor lesion. MRI demonstrated a T10 body and posterior element lesion with cord compression. A CT scan with the typical picture of 'polka dot' can be seen on axial cut. Biopsy confirmed the diagnosis of vertebral hemangioma. Preop embollization, decompression, vertebroplasty and posterior stabilization was done. One week post-op, her condition improved significantly. At six weeks post-op her condition was back to normal. Spinal hemangioma may affect all levels of the vertebrae with a predilection towards the thoracic region. MRI plays an important role, especially in looking at the extension of cord compression and presence of extraosseus lesion. An inactive lesion consist mainly of fatty tissue which give a hyperintense signal on both T1 and T2 weighted images. Treatment options range from radiotherapy, embolisation and surgery. Our goal of treatment in this patient was to decompress the spinal cord and achieved a stable spine. Persistent chronic back pain months after a compression fracture should raise our suspicion to pathological cause. Further investigation must be carried out to confirm the diagnosis.

KEYWORDS: vertebral hemangioma, cord compression 